\title{
A Rare Case Report of Gestational Gigantomastia
}

\author{
Kala A ${ }^{1}$, Rathna Arumugam², Kesari Sravani ${ }^{3}$
}

${ }^{1}$ Associate Professor, Department of Obstetrics and Gynaecology, Meenakshi Medical College Hospital and Research Institute, Kanchipuram, Tamilnadu, India. ${ }^{2}$ Postgraduate Student, Department of Obstetrics and Gynaecology, Meenakshi Medical College Hospital and Research Institute, Kanchipuram, Tamilnadu, India. ${ }^{3}$ Postgraduate Student, Department of Obstetrics and Gynaecology, Meenakshi Medical College Hospital and Research Institute, Kanchipuram, Tamilnadu, India.

\section{INTRODUCTION}

Gestational gigantomastia is a rare disorder characterised by excessive and rapid enlargement of both the breasts resulting in oedema and venous congestion of the breast tissue seen in pregnancy mainly during the second trimester. True gigantomastia develops rapidly during pregnancy, undergoes regression after delivery, and recurs with a subsequent pregnancy. ${ }^{1}$

\section{PRESENTATION OF CASE}

20 yrs. old Mrs. X, pimigravida, married for 10 months presented to our antenatal clinic at 19 wks. of gestation with excessive enlargement of breasts since the second month of conception. The swelling started insidiously and progressed. There was no itching or pain initially. She subsequently developed pain, itching and discomfort in her breasts, neck and back with marked limitation of movement. Past medical history was unremarkable.

On examination, she is thin built and moderately nourished, not anaemic, no lymphadenopathy. On inspection, both the breasts were uniformly enlarged. The skin appeared reddish, and there were no ulcerations or necrosis. The nipple was flattened, and the areola was increased in diameter. On palpation, both the breasts were soft in consistency. Measurements from R. Axilla to R side nipple was $28 \mathrm{cms}$ and L. Axilla to L side of the nipple was $30 \mathrm{cms}$. (Fig. 1) R breast circumference was $51 \mathrm{cms}$, and L breast circumference was $54 \mathrm{cms}$ (Fig. 2).

On per abdomen examination, the uterus was corresponding to the period of gestation with good foetal heart sounds. There was no organomegaly. Systemic examination was done, and other comorbidities were ruled out. Haemogram, urine analysis, renal profile and LFT and hormone studies were normal. Ultrasonography showed both the breast to be oedematous, showed heterogeneous echogenicity with few dilated inflammatory ducts. There was no sonological evidence of significant axillary lymphadenopathy as there were no signs of any ulceration or necrosis of the breast tissue.

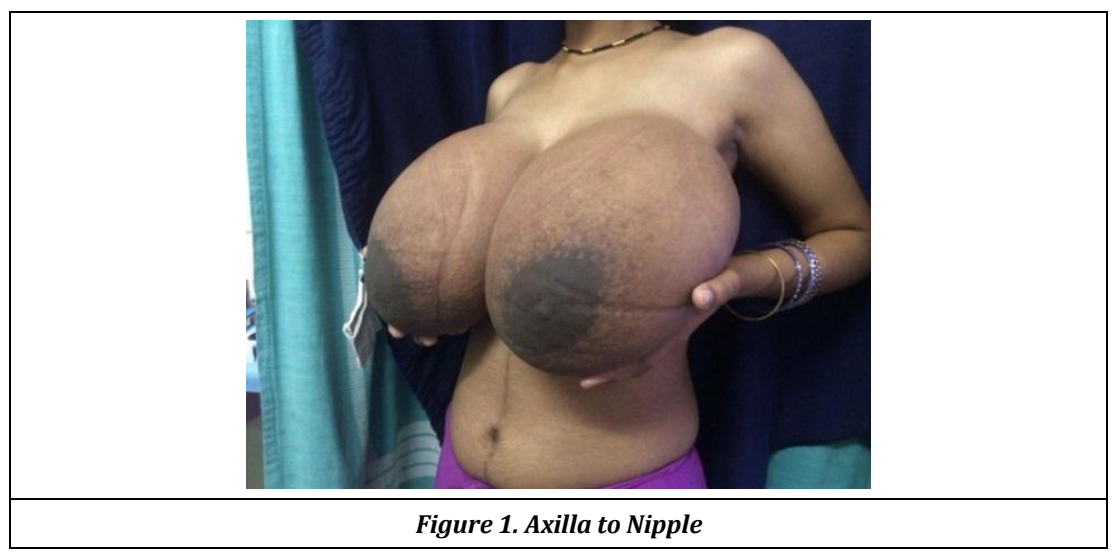

Corresponding Author: Dr. Rathna Arumugam, New Girls Hostel,

Meenakshi Medical College,

Enathur, Kanchipuram-631552,

Tamilnadu, India.

E-mail:rathna.dr@gmail.com

DOI: $10.14260 /$ jemds/2019/601

Financial or Other Competing Interests: None.

How to Cite This Article:

Kala A, Arumugam R, Sravani K. A rare case report of gestational gigantomastia. J. Evolution Med. Dent. Sci. 2019;8(35):27732774, DOI: 10.14260/jemds/2019/601

Submission 29-04-2019,

Peer Review 14-08-2019,

Acceptance 20-08-2019,

Published 02-09-2019. 


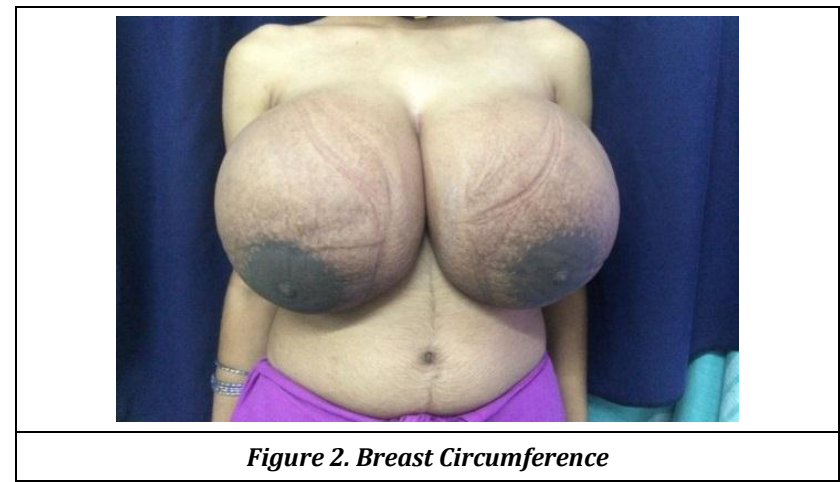

\section{DISCUSSION}

Aetiology is unknown. An incidence of 1 in 28,000 to 1 in 100,000 pregnancies has been quoted. Caucasian women are more likely to be affected than African-American women. The underlying cause of the rapidly growing connective tissue is thought to be due to increased sensitivity to prolactin, oestrogen and progesterone. It is more common in patients with autoimmune conditions such as myasthenia gravis, systemic lupus erythematosus, rheumatoid arthritis or autoimmune thyroiditis. Patients with gigantomastia may develop breast ulceration, haemorrhage, pain, cellulitis, decreased mobility, and situational depression. Microscopic examination of breast tissue most often shows glandular hyperplasia, overgrowth of connective tissue and tissue fibrosis. These findings are consistent with normal breast tissue changes during pregnancy. ${ }^{2}$ Adenosis- an increased number of acinar units per lobule and fibroadenomas, hormonally responsive intralobular stromal tumours are also frequently identified.

Medical therapies are inconsistent in the outcome. In most of the cases, Bromocriptine has been used. Although no major side effects have been reported some isolated case reports suggest intrauterine growth retardation. Numerous other drugs, 2 Br-alpha ergocryptine has been used. Although no major side effects have been reported, some isolated case reports suggest intrauterine growth retardation. Numerous other drugs, $2 \mathrm{Br}$-alpha ergocryptine, androgens, oestrogens, and progesterone norethindrone, stilbestrol and tamoxifen have also been tried but with limited success. ${ }^{3}$ However, if the patient and foetus are experiencing significant morbidity when complications such as massive haemorrhage, ulceration or breast necrosis occur, then surgical intervention is warranted. Gigantomastia makes breastfeeding impossible, a serious problem in developing countries where poverty limits the provision of alternatives to breast milk. Typically, it may resolve itself without treatment after completion of pregnancy, but few patients may require reduction mammoplasty or mastectomy during pregnancy, and breast reconstruction during puerperium based on the severity of the condition. If the mother is considering future pregnancies mastectomy offers the lowest risk of recurrence.

\section{DISCUSSION OF MANAGEMENT}

The patient was counselled, reassurance was given, adequate breast support was advised, and analgesics were prescribed. She was also started on T. Bromocriptine $2.5 \mathrm{mg}$ BD.

\section{REFERENCES}

[1] Mangia M, Singla D. Gestational gigantomastia. a systematic review of case reports. Journal of Mid-Life Health 2017;8(1):40-4.

[2] Ezem BU, Osuagwu CC, Opera KA. Gestational gigantomastia with complete resolution in a Nigerian woman. BMJ Case Reports 2011;2011: pii: bcr0120102632.

[3] Agarwal N, Kriplani A, Gupta A, et al. Management of gigantomastia complicating pregnancy. A case report. The Journal of Reproductive Medicine 2002;47(10):871-4. 